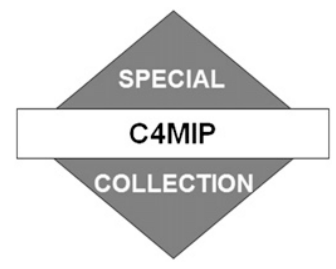

\title{
Uncertainties in CMIP5 Climate Projections due to Carbon Cycle Feedbacks
}

\author{
Pierre Friedlingstein, ${ }^{*}$ Malte Meinshausen, ${ }^{+}$Vivek K. Arora, ${ }^{\#}$ Chris D. Jones, ${ }^{@}$ \\ AlESSANDRo ANAV, $*$ SPENCER K. LidDicoAT, ${ }^{@}$ AND RETO KNUTTI ${ }^{\&}$ \\ * College of Engineering, Mathematics and Physical Sciences, University of Exeter, Exeter, United Kingdom \\ ${ }^{+}$Potsdam Institute for Climate Impact Research (PIK), Potsdam, Germany, and School of Earth Sciences, \\ University of Melbourne, Melbourne, Victoria, Australia \\ \# Canadian Centre for Climate Modelling and Analysis, Environment Canada, University of Victoria, \\ Victoria, British Columbia, Canada \\ ${ }^{\circledR}$ Met Office Hadley Centre, Exeter, United Kingdom \\ ${ }^{\&}$ Institute for Atmospheric and Climate Science, ETH Zurich, Zurich, Switzerland
}

(Manuscript received 31 July 2012, in final form 4 September 2013)

\begin{abstract}
In the context of phase 5 of the Coupled Model Intercomparison Project, most climate simulations use prescribed atmospheric $\mathrm{CO}_{2}$ concentration and therefore do not interactively include the effect of carbon cycle feedbacks. However, the representative concentration pathway 8.5 (RCP8.5) scenario has additionally been run by earth system models with prescribed $\mathrm{CO}_{2}$ emissions. This paper analyzes the climate projections of 11 earth system models (ESMs) that performed both emission-driven and concentration-driven RCP8.5 simulations. When forced by RCP8.5 $\mathrm{CO}_{2}$ emissions, models simulate a large spread in atmospheric $\mathrm{CO}_{2}$; the simulated 2100 concentrations range between 795 and $1145 \mathrm{ppm}$. Seven out of the 11 ESMs simulate a larger $\mathrm{CO}_{2}$ (on average by $44 \mathrm{ppm}, 985 \pm 97 \mathrm{ppm}$ by 2100) and hence higher radiative forcing (by $0.25 \mathrm{~W} \mathrm{~m}^{-2}$ ) when driven by $\mathrm{CO}_{2}$ emissions than for the concentration-driven scenarios $(941 \mathrm{ppm})$. However, most of these models already overestimate the present-day $\mathrm{CO}_{2}$, with the present-day biases reasonably well correlated with future atmospheric concentrations' departure from the prescribed concentration. The uncertainty in $\mathrm{CO}_{2}$ projections is mainly attributable to uncertainties in the response of the land carbon cycle. As a result of simulated higher $\mathrm{CO}_{2}$ concentrations than in the concentration-driven simulations, temperature projections are generally higher when ESMs are driven with $\mathrm{CO}_{2}$ emissions. Global surface temperature change by 2100 (relative to present day) increased by $3.9^{\circ} \pm 0.9^{\circ} \mathrm{C}$ for the emission-driven simulations compared to $3.7^{\circ} \pm$ $0.7^{\circ} \mathrm{C}$ in the concentration-driven simulations. Although the lower ends are comparable in both sets of simulations, the highest climate projections are significantly warmer in the emission-driven simulations because of stronger carbon cycle feedbacks.
\end{abstract}

\section{Introduction}

In the Fourth Assessment Report of the Intergovernmental Panel on Climate Change (IPCC AR4), the best guess and likely range (66\% probability) of global temperature warming by 2100 were $1.8(1.1-2.9)$, 2.4 (1.4 $3.8), 2.4(1.4-3.8), 2.8(1.7-4.4), 3.4(2.0-5.4)$, and $4.0(2.4$ 6.4) for the B1, B2, A1T, A1B, A2, and A1FI illustrative Special Report on Emissions Scenarios (SRES), respectively (Meehl et al. 2007). One can easily note that the

Corresponding author address: Pierre Friedlingstein, College of Engineering, Mathematics and Physical Sciences, University of Exeter, North Park Road, Exeter EX4 4QF, United Kingdom. E-mail: p.friedlingstein@exeter.ac.uk best guess is not centered in the likely range interval; the distribution is asymmetrical with a $-40 /+60 \%$ distribution around the best estimate (i.e., the average of the likely range is $10 \%$ above the best estimate). This asymmetrical " $-40 /+60 \%$ " distribution was based on several lines of evidence as described in detail in Knutti et al. (2008). It was argued that the projected warming as simulated by 23 atmosphere-ocean general circulation models (AOGCMs) at that time, as part of the World Climate Research Programme's phase 3 of the Coupled Model Intercomparison Project (WCRP CMIP3) (Meehl et al. 2007), did not explore the full range of possible warming for a given scenario. Although estimating such a full range is virtually impossible, one can use other lines of evidence to estimate whether the full uncertainty 
ranges are offset (i.e., to correct a potential bias), are wider (i.e., to reflect additional uncertainties), and/or are more or less skewed (i.e., to reflect additional skewed uncertainties).

When providing best-estimate projections and uncertainty ranges for emission scenarios, there are two major sources of uncertainty that need to be taken into account. The first relates to physical processes and feedbacks, and the uncertainty they induce on climate response for a given greenhouse gas (GHG) concentration and aerosol forcing in terms of the global-mean temperature response, and regional climate change; while the second relates to carbon cycle processes and feedbacks, with the associated uncertainty on the relationship between $\mathrm{CO}_{2}$ emissions and $\mathrm{CO}_{2}$ concentration.

A lack of understanding and observations of physical feedbacks reflected in model spread is indeed the main source of uncertainty in long-term climate projections (e.g., Hawkins and Sutton 2009). While the initial Planck response to an increase in atmospheric $\mathrm{CO}_{2}$ is known, the cascade of feedbacks arising from the warminginduced changes in water vapor, lapse rate, clouds, snow, and ice is far from being completely understood (Bony et al. 2006). The equilibrium climate sensitivity (ECS), defined as the equilibrium global mean surface warming for a doubling of atmospheric $\mathrm{CO}_{2}$, was estimated to be $3.3^{\circ} \pm 0.7^{\circ} \mathrm{C}(1 \sigma$,$) for the slab ocean versions of CMIP3$ climate models included in the IPCC AR4 (Meehl et al. 2007). A lower mean ECS was found for the coupled model versions and estimated to be $2.8^{\circ} \mathrm{C}$ by Forster and Taylor (2006) and $2.9^{\circ} \mathrm{C}$ by Meinshausen et al. (2011a). Taking into account multiple lines of evidence, the IPCC AR4 concluded: "The equilibrium climate sensitivity is likely to be in the range $2^{\circ} \mathrm{C}$ to $4.5^{\circ} \mathrm{C}$ with a best estimate of about $3^{\circ} \mathrm{C}$, and is very unlikely to be less than $1.5^{\circ} \mathrm{C}$. Values substantially higher than $4.5^{\circ} \mathrm{C}$ cannot be excluded, but agreement of models with observations is not as good for those values" (Solomon et al. 2007, p. 12). ECS being outside the CMIP3 range was possibleand in particular, no very likely statement was given for the upper end of the range.

The second major cause for uncertainties relates to the global carbon cycle. CMIP3 models were driven by $\mathrm{CO}_{2}$ concentrations along with non- $\mathrm{CO}_{2}$ GHG and aerosol forcing for each SRES scenario (Nakicenovic et al. 2000) provided by a former version of the Bern carbon cycle-climate model (Bern-CC). In the real world, changes in atmospheric $\mathrm{CO}_{2}$ concentration result from the imbalance between $\mathrm{CO}_{2}$ emissions from fossil fuel burning and deforestation (Friedlingstein et al. 2010; Peters et al. 2012) and $\mathrm{CO}_{2}$ uptake by the oceans and the terrestrial biosphere (Le Quéré et al. 2009; Denman et al. 2007). Processes controlling these uptakes as well as their response to change in atmospheric composition (mainly $\mathrm{CO}_{2}$ ) and climate are far from being well understood. For about two decades now, land and ocean carbon cycle models have been attempting to simulate the historical and/or future evolution of the carbon cycle with very modest improvement in terms of uncertainty reduction (e.g., VEMAP 1995; Cramer et al. 2001; Orr et al. 2001; Friedlingstein et al. 2006; Sitch et al. 2008). At the time of AR4, the Coupled Carbon Cycle Climate Model Intercomparison Project ( $\left.{ }^{4} \mathrm{MIP}\right)$ highlighted the large uncertainty in future projections of the carbon cycle (Friedlingstein et al. 2006). Starting from the same historical and twenty-first-century anthropogenic emissions of $\mathrm{CO}_{2}, 11$ carbon cycle climate models (hereafter $\mathrm{C}^{4} \mathrm{MIP}$ models; model names listed in Table 1) simulated atmospheric $\mathrm{CO}_{2}$ ranging between 700 and 1000 ppm by 2100 for the SRES A2 emission scenario. Reasons for this large range were mainly due to the large uncertainty in the response of land carbon cycle to increasing $\mathrm{CO}_{2}$ (carbon-concentration feedback) and climate change (carbon-climate feedback) (Friedlingstein et al. 2006; Gregory et al. 2009). Ocean carbon cycle models showed a more consistent picture. However, two models [L'Institut Pierre-Simon Laplace Coupled Model, version 2C (IPSL-CM2C) and University of Maryland (UMD)] showed a substantial deviation from the bulk of the $\mathrm{C}^{4} \mathrm{MIP}$ models, featuring substantially higher ocean carbon uptake. Nevertheless, it was found that on average, the $\mathrm{C}^{4} \mathrm{MIP}$ models were simulating a larger atmospheric $\mathrm{CO}_{2}$ than the one prescribed to the standard CMIP3 climate models used in AR4 for climate projections, at that time based on a reference simulation with the Bern-CC. As a result, the $\mathrm{C}^{4} \mathrm{MIP}$ warming range was higher than the CMIP3 models' warming range, and critically important, it was found that the upper end of the $\mathrm{C}^{4}$ MIP models' warming was significantly larger than the one simulated by the CMIP3 models (Meehl et al. 2007).

The combined uncertainty in climate response and carbon cycle response led to a decision, based on expert judgment, to expand the range of global temperature projections (Meehl et al. 2007; Knutti et al. 2008). The CMIP3 multimodel average was used, but the range was calculated using a $-40 \% /+60 \%$ scaling factor as discussed above. The choice of those particular values was also based on a number of different quantitative methods using a variety of models and statistical methods, considering uncertainties in radiative forcing, climate feedbacks, ocean heat uptake, and the carbon cycle derived from models and observations (see Knutti et al. 2008, and references therein).

The World Climate Research Programme's phase 5 of the CMIP (CMIP5) is the main resource for the IPCC 
AR5 assessment of climate projection. Even if the models perform well, there is no a priori reason that an ensemble of opportunity, in which the sampling of the models is not designed in any particular way, should cover all the relevant uncertainties (Tebaldi and Knutti 2007). We investigate whether a potential offset is necessary, by comparing the earth system models' (ESMs) results of the emission-driven CMIP5 runs to the prescribed $\mathrm{CO}_{2}$ concentrations, and put that in the context of the findings at the time of the IPCC AR4. The aim of this paper is to describe the CMIP5 simulations driven by $\mathrm{CO}_{2}$ emissions and to analyze their results in terms of the carbon cycle response, thereby assessing whether the standard CMIP5 climate simulations (with prescribed atmospheric $\mathrm{CO}_{2}$ ) might have resulted in significantly different climate projection ranges if they were emissiondriven-not concentration driven-experiments. The assessment of CMIP5 models' transient climate response and whether it does explore the possible range, as well as an assessment of potential bias in non- $\mathrm{CO}_{2}$ forcing (e.g., aerosols), are not in the scope of this paper. Hence, this paper will not give a definitive answer on what scaling would have to be used if the CMIP5 results should be transformed to estimated climate projections for emission-driven runs. We will only attempt to quantify the additional uncertainty arising from the carbon cycle.

Section 2 below describes the CMIP5 experiments used here; section 3 presents the historical simulations and their evaluation against observations; sections 4 and 5 analyze the twenty-first-century changes in $\mathrm{CO}_{2}$, temperature, and the global carbon cycle.

\section{CMIP5 experiments, emission-driven protocol, and model implementations}

Despite the importance of the carbon cycle and its feedback on the climate system, the CMIP5 experiment protocol was designed to allow participation of groups having a climate model without an interactive carbon cycle as well as groups having an ESM including the global carbon cycle (Hibbard et al. 2007; Taylor et al. 2012). Most of the proposed experiments are performed using prescribed globally averaged $\mathrm{CO}_{2}$ concentration, not $\mathrm{CO}_{2}$ emissions, allowing participation of both AOGCMs and ESMs. For a given model, the projected climate change is then independent of the strength of its feedbacks associated with the carbon cycle. Concentrationcarbon and climate-carbon feedbacks would affect the carbon fluxes between the atmosphere and the underlying land and ocean simulated by an ESM, but these would not affect the atmospheric $\mathrm{CO}_{2}$ concentration as it is prescribed. With an ESM, from the prescribed atmospheric $\mathrm{CO}_{2}$ growth rate and the simulated land and ocean carbon fluxes, one can diagnose the $\mathrm{CO}_{2}$ emissions compatible with the prescribed $\mathrm{CO}_{2}$ concentrations (Matthews 2005, 2006; Jones et al. 2006, 2013). The magnitude of the emissions compatible with the RCP concentrations would be affected by the carbon cycle feedbacks; a model with a large negative climatecarbon cycle feedback would have lower sinks, and hence lower compatible emissions (Jones et al. 2013). Four concentration-driven ( $\mathrm{C}$ driven) scenarios were proposed for the twenty-first century and beyond, the representative concentration pathways (RCPs) 2.6, 4.5, 6.0, and 8.5 (Moss et al. 2010; van Vuuren et al. 2011; Meinshausen et al. 2011c). Integrated assessment models (IAM) simulated the greenhouse gas and aerosol emissions for these four RCPs scenarios (van Vuuren et al. 2011). These emissions were harmonized with historical estimates and then translated into concentrations using the Model for the Assessment of Greenhouse Gas Induced Climate Change, version 6 (MAGICC6) (Meinshausen et al. 2011a,b,c). MAGICC6 is a simple climate model that also includes a representation of the global carbon cycle and atmospheric chemistry. The carbon cycle is composed of three land carbon pools, an ocean carbon component, and multiple temperaturedependent terrestrial and oceanic carbon fluxes, as well as a parameterization for the $\mathrm{CO}_{2}$ fertilization effect. Through the optimization of several parameters, MAGICC6 can closely reproduce the temporal behavior of higher-complexity physical climate and climatecarbon cycle models [see Meinshausen et al. (2011a) for details on the optimization method]. For the CMIP5 experiments, MAGICC6 used a multimodel average setup of parameters for climate sensitivity, combined with the carbon cycle emulation of the Bern-CC (Joos et al. 2001) taken as the "best estimate" for the carbon cycle behavior. This is essentially because the Bern-CC and its earlier versions have been used for the consolidated concentrations of IPCC SRES scenarios presented in the Third Assessment Report (Prentice et al. 2001; see also appendix II in Houghton et al. 2001).

The CMIP5 protocol recommended that only one scenario, the RCP8.5, be run twice, with $\mathrm{CO}_{2}$ concentration as well as with $\mathrm{CO}_{2}$ emissions as a forcing (Taylor et al. 2012). For these emission-driven simulations, historical $\mathrm{CO}_{2}$ emissions of fossil fuel (Andres et al. 2011) and land use change emissions (Houghton 2010, and updates) as well as twenty-first-century emissions for RCP8.5 (https://tntcat.iiasa.ac.at:8743/RcpDb . This allows a formal comparison between their simulated climate when atmospheric $\mathrm{CO}_{2}$ concentration is prescribed $(\mathrm{C}$ driven runs) and when atmospheric $\mathrm{CO}_{2}$ concentration is calculated from the balance between prescribed $\mathrm{CO}_{2}$ 


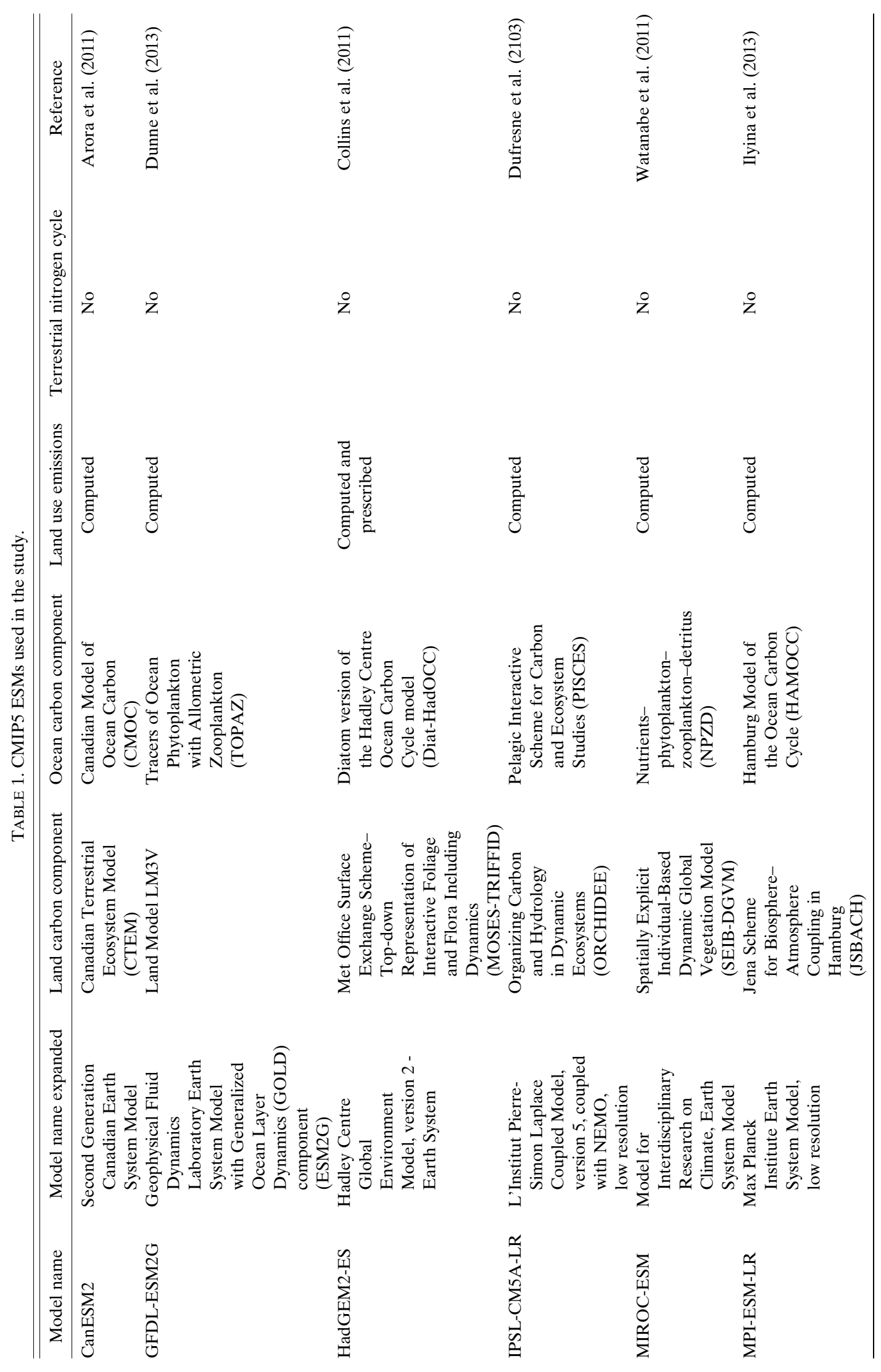




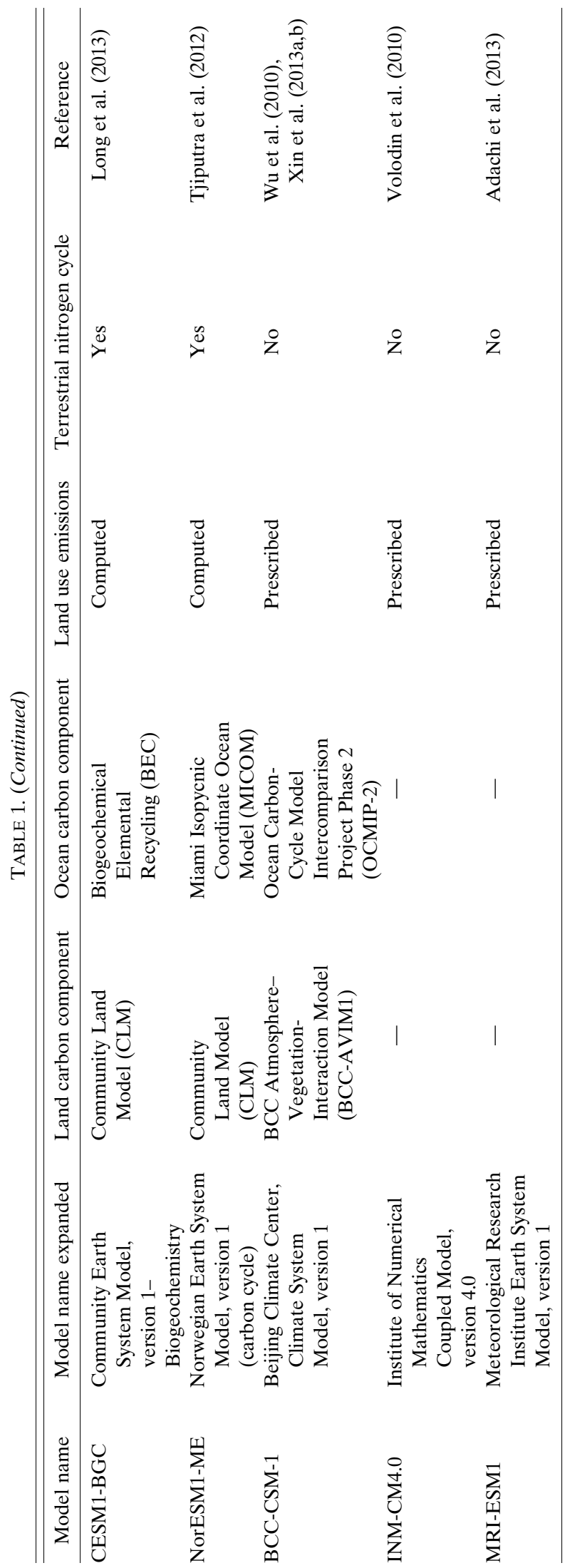

emissions and the simulated atmosphere-land and atmosphere-ocean $\mathrm{CO}_{2}$ fluxes [emission (E)-driven run]. Several modeling groups have performed these two RCP8.5 simulations. Results from 11 ESMs are analyzed here and their main characteristics are listed in Table 1.

Although conceptually simple, the implementation of the E-driven runs was not identical for all models-in particular, with respect to the treatment of the land use change (LUC). Land cover change (LCC) was provided as a standard CMIP5 forcing for all models for the historical period and for each RCP scenario (Hurtt et al. 2006; cmip-pcmdi.llnl.gov/cmip5/forcing.html). This allows ESMs to calculate $\mathrm{CO}_{2}$ emissions that result from the imposed changes in land cover, taking into account that deforestation leads to a direct emission of $\mathrm{CO}_{2}$ as well as indirect emissions due to soil degradation and the later decay of wood products (e.g., McGuire et al. 2001). Conversely, reforestation leads to an initial increase in simulated wood biomass followed by an increase in soil carbon, as the rate of litter fall in forests is higher than for croplands. In addition, tillage in croplands implies that litter and soil decomposition rates are higher over croplands than in forests. Not all models simulate all the LUC-related processes that affect $\mathrm{CO}_{2}$ emissions. Models that do not explicitly calculate LUC emissions can adopt an alternative approach, where LUC $\mathrm{CO}_{2}$ emissions are prescribed as an external forcing in a manner similar to $\mathrm{CO}_{2}$ fossil fuel emissions.

The vertically integrated globally averaged carbon budget equation for the atmosphere is written as

$$
\frac{d C_{A}}{d t}=E_{F}-F_{o}-F_{L}=\left(E_{F}+E_{\mathrm{LUC}}\right)-F_{o}-F_{\mathrm{Ln}},
$$

where $C_{A}$ is the global atmospheric carbon burden $(\mathrm{PgC}) ; F_{O}$ and $F_{L}$ are the atmosphere-ocean and atmosphere-land $\mathrm{CO}_{2}$ fluxes $\left(\mathrm{PgC} \mathrm{yr}^{-1}\right)$, respectively; and $E_{F}$ is the rate of anthropogenic fossil fuel emissions $\left(\mathrm{PgC} \mathrm{yr}^{-1}\right)$, which was prescribed for all ESMs. The modeled atmosphere-land $\mathrm{CO}_{2}$ flux is represented as $F_{L}=F_{\mathrm{Ln}}-E_{\mathrm{LUC}}$, where $E_{\mathrm{LUC}}$ is the flux (assumed positive into the atmosphere) due to anthropogenic land use change and $F_{\mathrm{Ln}}$ is the natural component, also referred to as the residual land sink (RLS) in Le Quéré et al. (2012). The net exchange of $\mathrm{CO}_{2}$ between the atmosphere and the land surfaces, $F_{L}$, is often referred as the net biome production (NBP).

Seven out of the 11 ESMs analyzed here interactively simulated LUC $\mathrm{CO}_{2}$ emissions $\left(E_{\mathrm{LUC}}\right)$ from the prescribed land cover change (see Table 1). For these models, only the $F_{L}$ field is provided and not its separate components (i.e., $E_{\mathrm{LUC}}$ and $F_{\mathrm{Ln}}$ ). The reason is that this separation requires doing an additional ESM simulation 

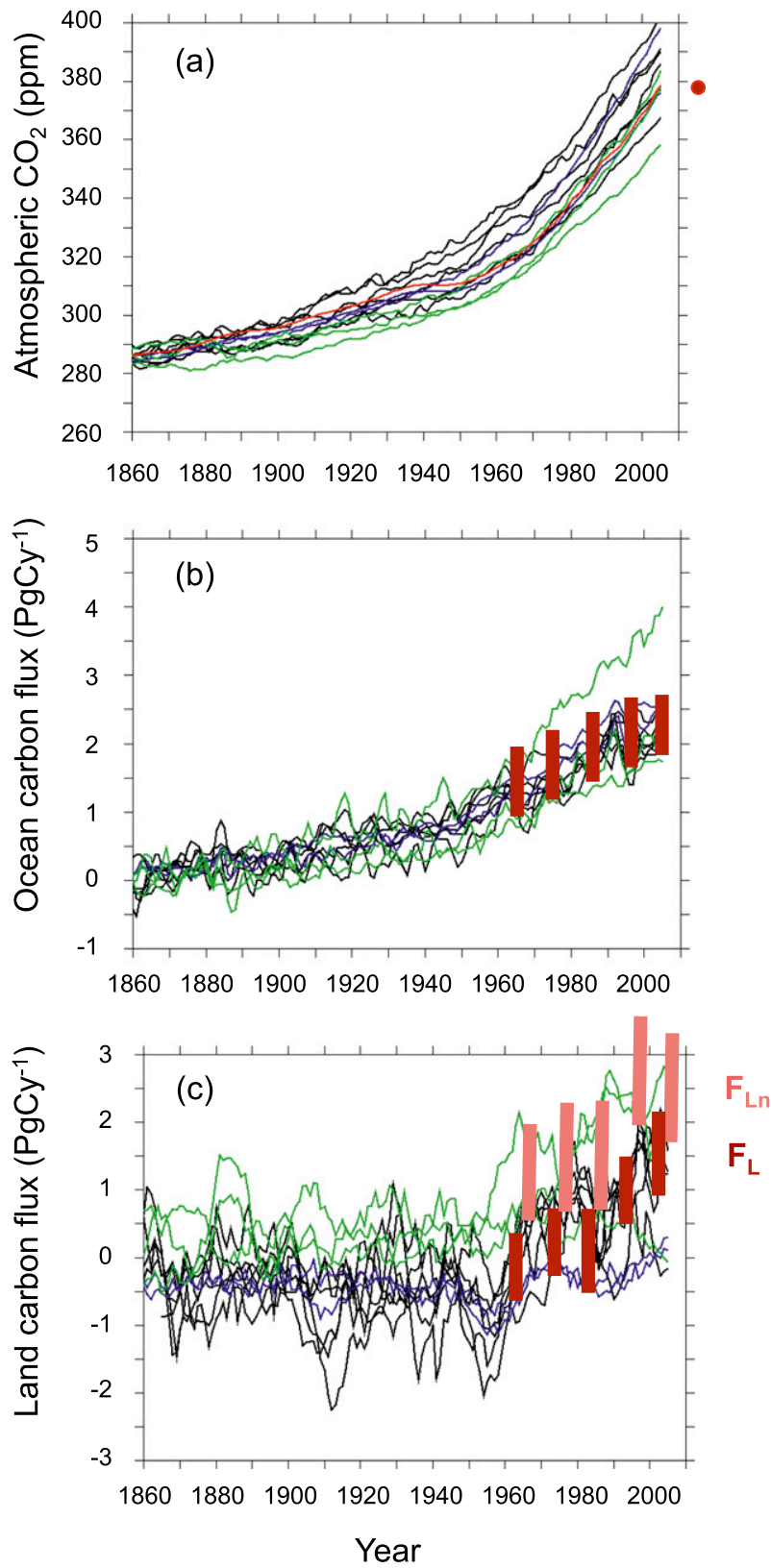

FIG. 1. Historical (a) atmospheric $\mathrm{CO}_{2}$ concentration (ppm), (b) air-ocean carbon net flux $\left(\mathrm{PgC} \mathrm{yr}^{-1}\right)$, and (c) air-land carbon net flux $\left(\mathrm{PgC} \mathrm{yr}^{-1}\right)$ simulated by the 11 ESMs. Data in red are the observational constraints. For the land, observations are both $F_{L}$ (dark red) and $F_{\text {Ln }}$ (light red) as estimated in Le Quéré et al. (2012). Blue lines are for ESMs accounting for a terrestrial nitrogen cycle; green lines are for ESMs prescribing the LUC emissions, hence calculating $F_{L}$, not $F_{\text {Ln }}$ (see Table 1).

in which land use change forcing is switched off-that is, a simulation with the same GHG and aerosols forcing but not including any land cover changes (e.g., Arora and Boer 2010).
Three ESMs (BCC-CSM-1, INM-CM4.0, and MRIESM1) prescribed both fossil fuel $\left(E_{F}\right)$ and LUC $\left(E_{\mathrm{LUC}}\right)$ emissions as an external forcing, not accounting for carbon fluxes resulting from land cover change in the model. One model (HadGEM2-ES) adopted a somewhat hybrid methodology, accounting for land cover changes, hence calculating $F_{L}=F_{\mathrm{Ln}}-E_{\mathrm{LUC}}$, but the change in atmospheric $\mathrm{CO}_{2}$ was calculated using the externally prescribed land use change emissions $\left(E_{\mathrm{LUC}}\right)$, potentially leading to inconsistency in the model but reducing the impact of any potential biases in the simulated land use flux. Finally, we note that while MRIESM1 used the externally prescribed LUC emissions, it nevertheless accounts for this prescribed loss of carbon following LUC in its total land carbon inventory. The different manners in which interactive land use change is implemented in ESMs imply that a direct comparison of simulated land use change emissions is not possible across models. These differences in model implementation of land use change need to be kept in mind when analyzing model results-in particular atmosphere-land $\mathrm{CO}_{2}$ fluxes, as not all models simulate the same quantity, although they are generally reported as the same variable, $F_{L}$ (NBP variable in the CMIP5 archive).

\section{Simulated atmospheric $\mathrm{CO}_{2}$ and carbon cycle over the historical period}

The models simulate the historical changes in atmospheric $\mathrm{CO}_{2}$ and carbon cycle in response to the prescribed anthropogenic perturbation. Fossil fuel emissions combined with the LUC forcing lead to a rapid increase in atmospheric $\mathrm{CO}_{2}$, similar to the observations. However, while the observed atmospheric $\mathrm{CO}_{2}$ reached 379 ppm by 2005 , the simulated atmospheric $\mathrm{CO}_{2}$ concentrations range between 358 (MRI-ESM1) and 403 ppm (HadGEM2-ES) for 2005, both underpredicting and overpredicting the historical atmospheric $\mathrm{CO}_{2}$ increase by more than $20 \%$ (Fig. 1a; Table 2). Only five models (BCC-CSM-1, CanESM2, INM-CM4.0, MPI-ESMLR, and NorESM1-ME) are within $10 \%$ of the observed $\mathrm{CO}_{2}$ increase. HadGEM2-ES, CESM1-BGC, GFDL-ESM2G, and MIROC-ESM are substantially above the observed concentration by 2005, while IPSL-CM5A-LR and the MRI-ESM1 are significantly below.

A priori, reasons for departure from the observed $\mathrm{CO}_{2}$ have to be found in the simulation of the land and ocean $\mathrm{CO}_{2}$ net fluxes $\left[F_{O}\right.$ and $F_{L}$ in Eq. (1)], assuming here that anthropogenic fossil fuel emissions provided in the CMIP5 protocol represents real-world historical emissions. A brief evaluation of the global atmosphere-land 
TABLE 2. Historical atmospheric $\mathrm{CO}_{2}$ (2005), cumulative land and ocean uptake (1850-2005) and average land and ocean uptake (199099) simulated by the 11 ESMs compared with the observation-based estimates (with ranges being $68 \%$ confidence intervals). Also shown are the multimodel mean and range $(1 \sigma)$.

\begin{tabular}{|c|c|c|c|c|c|}
\hline & $\mathrm{CO}_{2}(\mathrm{ppm})$ & $\begin{array}{c}\text { Cumulative land } \mathrm{C} \\
\text { uptake }(\mathrm{PgC})\end{array}$ & $\begin{array}{c}\text { Cumulative ocean } \mathrm{C} \\
\text { uptake }(\mathrm{PgC})\end{array}$ & $\begin{array}{l}\text { Land C uptake } \\
\left(\mathrm{PgC} \mathrm{yr}^{-1}\right)\end{array}$ & $\begin{array}{l}\text { Ocean C uptake } \\
\quad\left(\mathrm{PgC} \mathrm{yr}^{-1}\right)\end{array}$ \\
\hline CanESM2 & 386 & 28 & 91 & 1.2 & 1.7 \\
\hline GFDL-ESM2G & 391 & -47 & 135 & 0.8 & 2.2 \\
\hline HadGEM2-ES & 403 & -33 & 148 & 1.2 & 2.4 \\
\hline IPSL-CM5A-LR & 368 & 5.1 & 121 & 1.5 & 2.0 \\
\hline MIROC-ESM & 390 & -36 & 128 & 0.3 & 2.3 \\
\hline MPI-ESM-LR & 377 & -7 & 119 & 1.5 & 1.9 \\
\hline CESM1-BGC & 398 & -56 & 124 & -0.2 & 2.2 \\
\hline NorESM1-ME & 379 & -68 & 149 & -0.3 & 2.5 \\
\hline BCC-CSM-1.1* & 383 & $146^{*}$ & 91 & $2.3^{*}$ & 1.8 \\
\hline INM-CM4.0* & 378 & 55 & 189 & 0.6 & 3.3 \\
\hline MRI-ESM1* & 358 & $88^{*}$ & 78 & $2.6^{*}$ & 1.5 \\
\hline Models' average & $382 \pm 12$ & $-26 \pm 32 * *$ & $124 \pm 30$ & $0.8 \pm 0.7 * *$ & $2.2 \pm 0.5$ \\
\hline $\begin{array}{l}\text { Observation-based } \\
\text { estimates }\end{array}$ & 379 & $\begin{array}{l}\int F_{L}:-11 \pm 47 \\
\int F_{\mathrm{Ln}}: 139 \pm 90\end{array}$ & $141 \pm 27$ & $\begin{array}{c}F_{L}: 1.1 \pm 0.5 \\
F_{\mathrm{Ln}}: 2.7 \pm 0.7\end{array}$ & $2.2 \pm 0.4$ \\
\hline
\end{tabular}

* $F_{\mathrm{Ln}}$ estimated as no simulated LUC carbon flux in these ESMs.

** Multimodel average for land carbon is only based on the eight ESMs simulating $F_{L}$. Note that HadGEM2-ES and GFDL-ESM2G simulations start in 1860 and 1861 , respectively; $F_{L}$ refers to the net atmosphere-land $\mathrm{CO}_{2}$ flux, and $F_{\mathrm{Ln}}$ is the residual atmosphere-land $\mathrm{CO}_{2}$ flux in the absence of land use change.

and atmosphere-ocean $\mathrm{CO}_{2}$ fluxes is presented here, and we refer to Anav et al. (2013) for a more in-depth analysis of the carbon cycle in ESMs. The best estimates of the ocean sinks come from both cumulative carbon inventories over the historical period (Sabine et al. 2004, and updates) and from combined oceanic $\left(p \mathrm{CO}_{2}\right.$ measurements and oceanic inversions) and atmospheric estimates (atmospheric $\mathrm{O}_{2}$ measurements) for the recent decades (Le Quéré et al. 2012). Most ESMs simulate a (1850-2005) cumulative ocean sink ranging between 91 and $155 \mathrm{PgC}$ compared to the observation-derived sink of $141 \pm 27 \mathrm{PgC}$ (Table 2). The exceptions are INMCM4.0, which overestimates the ocean sink by more than a factor of $2(360 \mathrm{PgC})$, and CanESM2, which underestimates the ocean sink by about $30 \%$. The behavior of CanESM2 was already reported in Arora et al. (2011), where possible underestimation of the simulated sink was linked to the absence of marginal basins and continental shelves in the model. The large oceanic uptake simulated by INM-CM4.0 is not yet fully understood (E. M. Volodin 2013, personal communication). As shown in Anav et al. (2013), the main reason for discrepancy comes from the tropical ocean, where INMCM4 simulates a strong sink $\left(\sim 1 \mathrm{PgC} \mathrm{yr}^{-1}\right)$ in clear contradiction with the large $\mathrm{CO}_{2}$ outgassing $\left(-1 \mathrm{PgC} \mathrm{yr}^{-1}\right)$ observed. When looking at the decadal mean ocean sink, as estimated in Le Quéré et al. (2012), ESMs generally agree remarkably well with the observationbased oceanic uptake for the last five decades (Fig. 1b), again with the exception of INM-CM4.0, which overestimates the sink from the 1970s onward. CanESM2's lower-than-average oceanic uptake mainly occurs in the first half of the twentieth century.

The net atmosphere-land $\mathrm{CO}_{2}$ flux $\left(F_{L}\right)$ cannot be directly measured; it can only be estimated by mass balance difference (Fossil fuel emissions minus atmospheric and oceanic storage). Based on this mass balance, Arora et al. (2011) estimate that cumulated over the 1850-2005 period, $F_{L}$ amounts to $-11 \pm 47 \mathrm{PgC}$. Out of the eight models that interactively model LUC emissions, three models-GFDL-ESM2G, NorESM1ME, and CESM1-BGC-significantly underestimate $F_{L}$; these models simulate a larger land source (negative cumulative $F_{L}$ of $-47,-68$, and $-56 \mathrm{PgC}$, respectively, over the 1850-2005 period) than the observation-based land source (negative cumulative $F_{L}$ of $-11 \pm 47 \mathrm{PgC}$ ). For these three models, the simulated land residual sink $\left(F_{\text {Ln }}\right)$ does not compensate the simulated LUC source. This is clearly visible in Fig. 1c, where these three models simulate a near-zero $F_{\text {Ln }}$ over the 1990s and 2000s, while the observation-based estimate is 1 and $1.5 \mathrm{PgC} \mathrm{yr}^{-1}$, respectively.

Both NorESM1-ME and CESM1-BGC share the same land surface scheme, the Community Land Model (CLM), and therefore produce similar results in terms of land carbon fluxes. The lower-than-average land sink simulated by these two models is due to the limited response to increasing atmospheric $\mathrm{CO}_{2}$ concentration, as previously reported (Arora et al. 2013; Gillet et al. 2013). CLM accounts for a terrestrial nitrogen cycle (Thornton et al. 2009), a feature not included in any of the other ESMs. Inclusion of the nitrogen cycle generally 
leads to weaker land carbon uptake estimates (e.g., Zaehle et al. 2010), partly explaining the CLM model behavior. However, the main reason for failing to simulate a significant land sink is the very short residence time of litter and soil carbon in CLM, reducing the lag between the net primary productivity (NPP) increase and the heterotrophic respiration increase-that is, reducing the strength of the land sink (Taylor and Lloyd 1992; Friedlingstein et al. 1995; Thompson et al. 1996). The short soil carbon residence time of CLM was diagnosed through comparison against litterbag measurements (Bonan et al. 2013) as well as comparison of soil carbon spatial distribution against observations (Todd-Brown et al. 2013; Anav et al. 2013), leading to a weak land carbon sink (Keppel-Aleks et al. 2013). Globally, CLM total soil carbon content is less than half of the observations (Todd-Brown et al. 2013; Anav et al. 2013). GFDL-ESM2G also simulates a lower-thanobserved $F_{L}$ but for different reasons. Its vegetation and soil carbon storage (and hence turnover time) are comparable to observations, hence not responsible for the models' underestimation of $F_{L}$ (Dunne et al. 2013; Anav et al. 2013). As noted in Dunne et al. (2013), the GFDL ESM tends to underestimate the atmospheric $\mathrm{CO}_{2}$ seasonal cycle, potentially also leading to a relatively weak land uptake. We also note that GFDL-ESM2G has a more comprehensive treatment of land cover change than other ESMs (Shevliakova et al. 2009), accounting for transitions between primary forests, crops, pastures, and secondary forests as well as wood harvesting, which increases the simulated LUC emissions.

In summary, CESM1-BGC and to a lesser extend GFDL-ESM2G overestimate the atmospheric $\mathrm{CO}_{2}$ growth rate because of a lower-than-observed $F_{L}$. We do not have a clear explanation for the overestimation of atmospheric $\mathrm{CO}_{2}$ simulated by HadGEM2-ES. As noted before, HadGEM2-ES accounts for LCC in its calculated $F_{L}$; however, it used the prescribed LUC emissions combined with a diagnostic of the model $F_{\mathrm{Ln}}$ to update the atmospheric $\mathrm{CO}_{2}$. A bias in this hybrid method cannot be excluded at this stage, underestimation of the diagnosed LUC emissions in the model, subsequently replaced by higher prescribed LUC would lead to greater $\mathrm{CO}_{2}$ growth rate. MRI-ESM1 is at the lower end of the simulated historical $\mathrm{CO}_{2}$. This model has a lower-than-observed ocean $\mathrm{CO}_{2}$ flux, combined with a land $\mathrm{CO}_{2}$ flux at the lower end of the observation based range of $F_{\text {Ln }}$ (Table 2). Having weak land and ocean carbon sinks should lead to a larger-thanobserved atmospheric $\mathrm{CO}_{2}$, opposite of what MRI-ESM1 simulates here. Hence, the very large underestimation of the atmospheric $\mathrm{CO}_{2}$ remains unexplained. From a carbon budget point of view (sum of carbon stored in atmosphere, land, and ocean; estimated in Table 2), it seems that MRI-ESM1 has much lower anthropogenic emissions than BCC-CSM-1 and INM-CM4, the other two models that externally prescribed the land use change $\mathrm{CO}_{2}$ emissions.

\section{Twenty-first-century atmospheric $\mathrm{CO}_{2}$ and global temperature change}

When forced by $\mathrm{CO}_{2}$ emissions, the 11 ESMs simulate a $\mathrm{CO}_{2}$ concentration trajectory that does not necessarily follow the default $\mathrm{CO}_{2}$ concentration pathway, as provided for CMIP5 by MAGICC6 (Fig. 2a). This is expected since the response of the carbon cycle in CMIP5 ESMs to changes in $\mathrm{CO}_{2}$ and climate need not be same as the one simulated by MAGICC6 in its CMIP5 setting (median CMIP3 AOGCMs for its climate response and Bern-CC for its carbon cycle response) (Meinshausen et al. 2011c). Figure 2a shows the twenty-first-century time evolution of atmospheric $\mathrm{CO}_{2}$ for the $11 \mathrm{ESMs}$ that performed the E-driven RCP8.5 simulations. By 2100, five CMIP5 ESMs (BCC-CSM-1, INM-CM4.0, IPSLCM5A-LR, MPI-ESM-LR, and NorESM1-ME) simulate $\mathrm{CO}_{2}$ concentrations relatively close (within $5 \%$ of the change relative to preindustrial) to the default RCP concentrations that reach $941 \mathrm{ppm}$ by 2100 . Five models (CanESM2, CESM1-BGC, GFDL-ESM2G, HadGEM2ES, MIROC-ESM) simulate much higher $\mathrm{CO}_{2}$ than the default RCP8.5 $\mathrm{CO}_{2}$ concentrations by 2100 and only one-MRI-ESM1-simulates a much lower atmospheric $\mathrm{CO}_{2}$ (Table 3). By 2100, the multimodel average $\mathrm{CO}_{2}$ concentration is $985 \pm 97 \mathrm{ppm}$, with a median of about $970 \mathrm{ppm}$. Most of the CMIP5 ESMs simulate a larger $\mathrm{CO}_{2}$ when driven by $\mathrm{CO}_{2}$ emissions than the one provided for the concentration-driven scenarios.

It is worth noting that by 2005 , these five models already overestimated the $\mathrm{CO}_{2}$ concentration, while MRI-ESM1 already severely underestimated it, thus potentially pointing to a persistent bias in these six ESMs.

By 2100 , the largest $\mathrm{CO}_{2}$ concentration is obtained with MIROC-ESM, reaching 1149 ppmv by 2100-more than $200 \mathrm{ppm}$ higher than the amount of $\mathrm{CO}_{2}$ from MAGICC6 used in the concentration-driven simulations (see Table 2). MRI-ESM1 simulates a $\mathrm{CO}_{2}$ of 794 ppm by $2100-150$ ppm lower than the RCP 8.5 default value. This model severely underestimates the present-day $\mathrm{CO}_{2}$, with a 2005 concentration of $358 \mathrm{ppm}-$ more than $20 \mathrm{ppm}$ below the observed value, potentially indicating an issue in the protocol followed by this model.

In general there is a clear correlation between the models' bias in atmospheric $\mathrm{CO}_{2}$ by 2005 and the models' departure from the MAGICC6 $\mathrm{CO}_{2}$ by 2100 

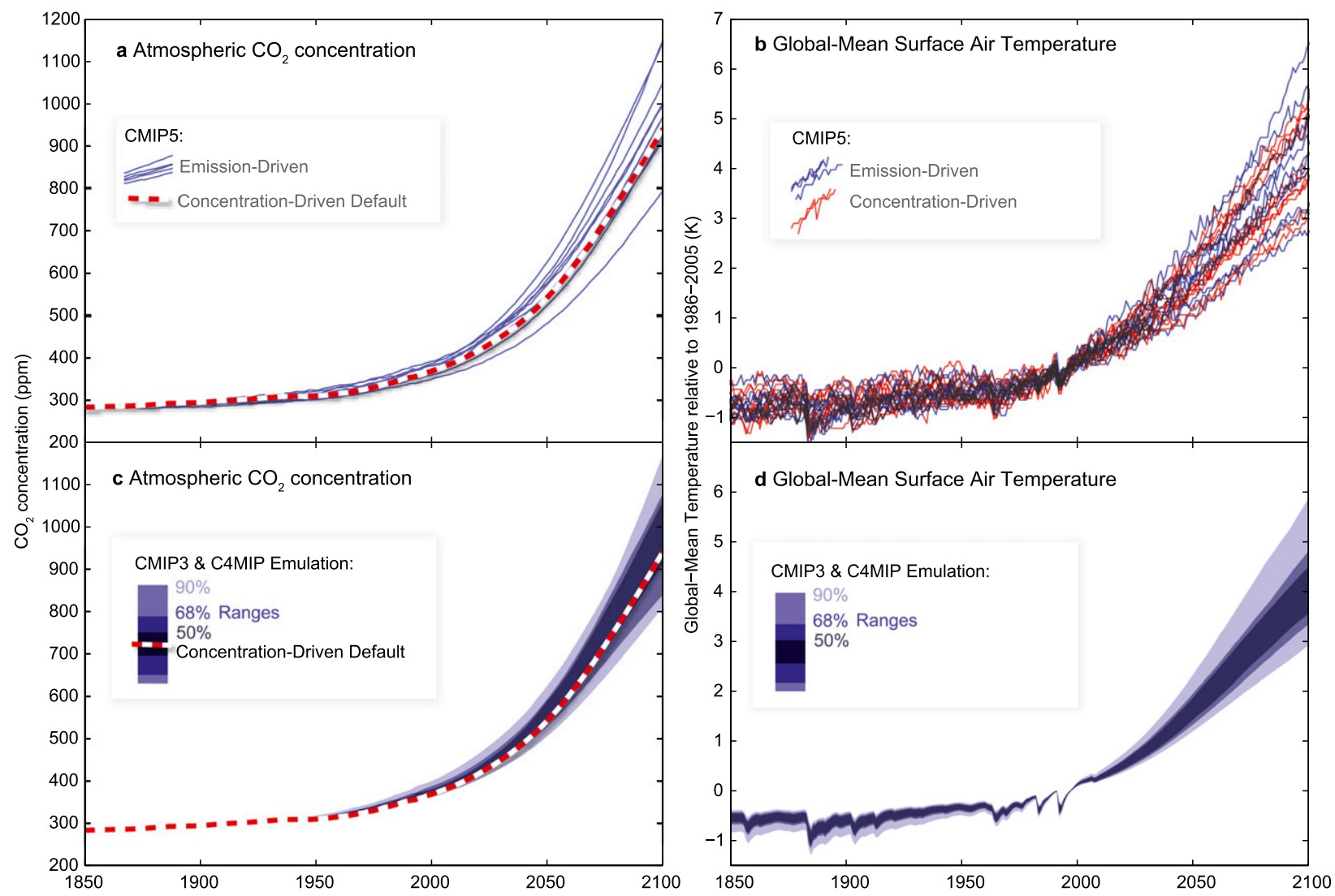

FIG. 2. Range of (a) simulated atmospheric $\mathrm{CO}_{2}$ (ppm) and (b) global surface temperature change (K) from the 11 ESMs E-driven (blue lines) and C-driven (red lines) simulations. Also shown is the full range of (c) simulated atmospheric $\mathrm{CO}_{2}$ (ppm) and (d) global surface temperature change (K) simulated by MAGICC6 when emulating all 19 CMIP3 climate models and 10 C ${ }^{4}$ MIP climate-carbon cycle models. The red-line curve in (a) and (c) is the baseline estimate from MAGICC6.

(Fig. 3). However, it should be noted that a model match with the present-day atmospheric $\mathrm{CO}_{2}$ does not imply that the model correctly simulates the land and the ocean carbon uptake. Indeed, INM-CM4.0 perfectly simulates the atmospheric $\mathrm{CO}_{2}$ concentration by 2005 , but because of a stronger-than-observed ocean sink combined with a weaker-than-observed land sink. The same applies to BCC-CSM-1 with, in that case, a weak ocean sink combined with a strong land sink.

The larger $\mathrm{CO}_{2}$ concentration simulated in the emissiondriven simulations induces an additional radiative forcing (multimodel average is $0.25 \pm 0.5 \mathrm{~W} \mathrm{~m}^{-2}$ ). The simulated warming in the E-driven run is therefore generally larger than the one simulated in the $\mathrm{C}$-driven runs of the same ESMs (Fig. 2b). For the C-driven simulations, the global surface temperature change (20812100 average relative to the 1986-2005 average) ranges between $2.6^{\circ}$ and $4.7^{\circ} \mathrm{C}$, with a multimodel average of $3.7^{\circ} \pm 0.7^{\circ} \mathrm{C}$ (Table 2). The E-driven simulations give a range of $2.5^{\circ}-5.6^{\circ} \mathrm{C}$, with a multimodel average of $3.9^{\circ} \pm$ $0.9^{\circ} \mathrm{C}$ - that is, $0.2^{\circ} \mathrm{C}$ larger than for the concentration-driven simulations. Three models-CanESM2, CESM1-BGC, and MIROC-ESM-have a strong warming amplification in the E-driven simulations, with an additional warming of $0.5^{\circ}, 0.5^{\circ}$ and $0.9^{\circ} \mathrm{C}$, respectively. HadGEM2-ES and MRI-ESM1 are the exceptions, both with a warming $0.4^{\circ} \mathrm{C}$ lower in the E-driven run than in the C-driven run. For MRI-ESM1, this is directly due to the lower simulated atmospheric $\mathrm{CO}_{2}$ in the emission-driven run. We note that HadGEM2-ES already overestimates presentday $\mathrm{CO}_{2}$ by about $25 \mathrm{ppm}$, partly explaining this unexpected behavior, as the warming shown here is only the increase above current warming levels (1986-2005), not since preindustrial times.

To put the CMIP5 model range into perspective of the IPCC AR4 range (Meehl et al. 2007), we used a large ensemble of MAGICC6 runs to emulate the $\mathrm{CO}_{2}$ and global temperature response one would get for the RCP8.5 scenario if generated by the IPCC AR4 models' runs (Figs. 2c and 2d). MAGICC6 was run by a uniform sampling of the climate sensitivity uncertainty taken from 19 CMIP3 models and the carbon cycle feedbacks uncertainty taken from $10 \mathrm{C}^{4} \mathrm{MIP}$ models, generating 190 model simulations (Meinshausen et al. 2011a). At 
TABLE 3. Twenty-first-century atmospheric $\mathrm{CO}_{2}$ (2100), global surface warming (2081-99 relative to 1986-2005), cumulative land and ocean uptake (1850-2100) for the E-driven simulations and global surface warming (2081-99 relative to 1986-2005) for the C-driven simulations (where atmospheric $\mathrm{CO}_{2}$ reaches $941 \mathrm{ppm}$ by 2100). Also shown are the multimodel mean and range $(1 \sigma)$ as well as the same quantities simulated by MAGICC6 in its reference setting.

\begin{tabular}{|c|c|c|c|c|c|}
\hline & $\begin{array}{c}\text { E-driven } \mathrm{CO}_{2} \\
(\mathrm{ppm})\end{array}$ & $\begin{array}{c}\text { E-driven } \\
\text { delta } T\left({ }^{\circ} \mathrm{C}\right)\end{array}$ & $\begin{array}{c}\text { E-driven } \\
\text { cumulative } \\
\text { land } \mathrm{C} \text { uptake } \\
(\mathrm{PgC})\end{array}$ & $\begin{array}{c}\text { E-driven } \\
\text { cumulative } \\
\text { ocean } \mathrm{C} \text { uptake } \\
(\mathrm{PgC})\end{array}$ & $\begin{array}{c}\text { C-driven delta } \\
T\left({ }^{\circ} \mathrm{C}\right)\end{array}$ \\
\hline CanESM2 & 1048 & 5.0 & 161 & 455 & 4.5 \\
\hline GFDL-ESM2G & 997 & 2.9 & 167 & 550 & 2.8 \\
\hline HadGEM2-ES & 998 & 4.3 & 352 & 543 & 4.7 \\
\hline IPSL-CM5A-LR & 926 & 4.5 & 300 & 555 & 4.5 \\
\hline MIROC-ESM & 1149 & 5.6 & -165 & 544 & 4.7 \\
\hline MPI-ESM-LR & 969 & 3.7 & 231 & 412 & 3.6 \\
\hline CESM1-BGC & 1142 & 4.1 & -145 & 541 & 3.6 \\
\hline NorESM1-M & 934 & 3.8 & -173 & 649 & 3.4 \\
\hline BCC-CSM-1* & 967 & 3.5 & $471 *$ & 490 & 3.3 \\
\hline INM-CM4.0* & 914 & 2.5 & 201 & 861 & 2.6 \\
\hline MRI-ESM1* & 794 & 2.9 & 758 & 528 & 3.3 \\
\hline Models average & $985 \pm 97$ & $3.9 \pm 0.9$ & $91 \pm 218^{* *}$ & $557 \pm 112$ & $3.7 \pm 0.7$ \\
\hline MAGICC6 & 941 & 4.0 & 204 & 617 & 4.0 \\
\hline
\end{tabular}

$* F_{\text {Ln }}$ estimated as no simulated LUC carbon flux in these ESMs.

** Multimodel average for land carbon is only based on the eight ESMs simulating $F_{L}$. HadGEM2-ES and GFDL-ESM2G simulations start in 1860 and 1861, respectively. Note that BCC-CSM-1 simulations end in 2099; the $2099-2098$ atmospheric $\mathrm{CO}_{2}$ difference was used to infer atmospheric $\mathrm{CO}_{2}$ by 2100 .

first glance, the range of atmospheric $\mathrm{CO}_{2}$ from the CMIP5 ESMs and from the MAGICC6 emulation of the CMIP3/ $\mathrm{C}^{4} \mathrm{MIP}$ models is quite similar (Figs. 2a and 2c) - in particular, both sets give a comparable upper estimate of the atmospheric $\mathrm{CO}_{2}$ concentration, about $1150 \mathrm{ppm}$ by 2100 . However, the comparison is not straightforward for the lower end of the projections. As already noted above, most ESMs simulate larger $\mathrm{CO}_{2}$ concentrations than the MAGICC baseline estimate (red line in Figs. 2a and 2c). For 2100, the range of $\mathrm{CO}_{2}$ concentrations is 794-1149 ppm for the 11 CMIP5 ESMs analyzed here, while the range ( $90 \%$ probability) for the

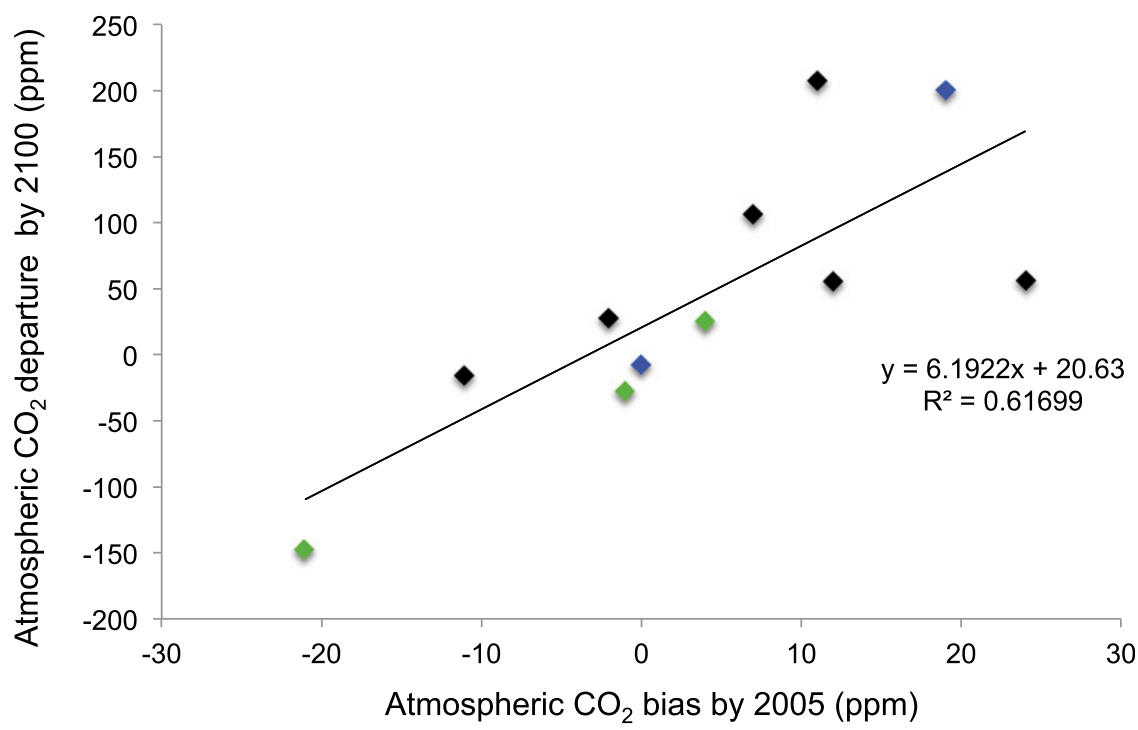

FIG. 3. Relationship between model bias in simulating present-day (2005) atmospheric $\mathrm{CO}_{2}$, and the difference between 2100 simulated $\mathrm{CO}_{2}$ and baseline estimate from MAGICC6 (941 ppm). Color code for model types is as in Fig. 1. Also shown is the linear regression along with correlation and regression coefficients. 

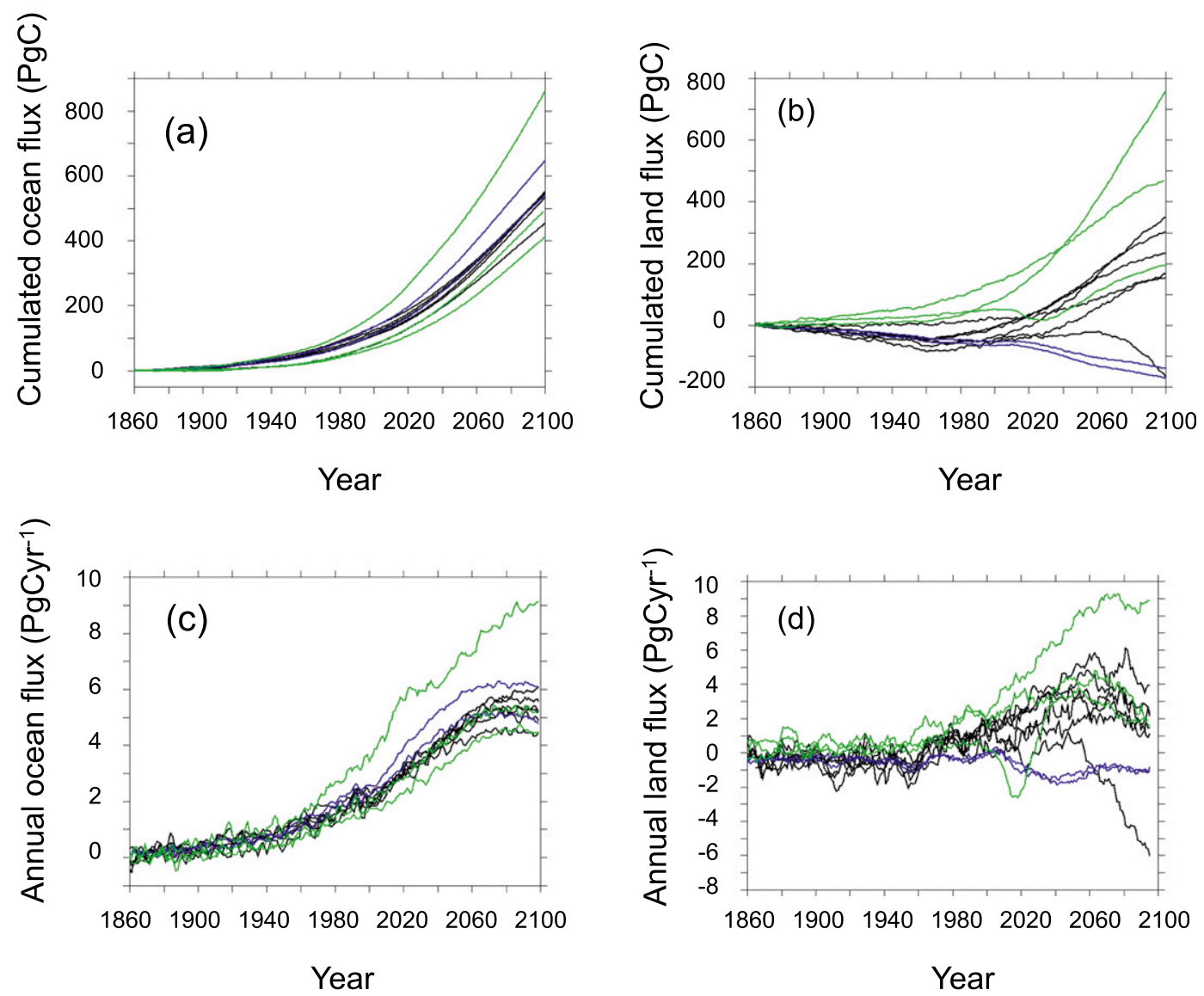

FIG. 4. Range of (a) cumulative global air to ocean carbon flux $(\mathrm{PgC})$, (b) cumulative global air to land carbon flux $(\mathrm{PgC})$ from the 11 ESMs E-driven simulations, (c) the annual global air to ocean carbon flux, and (d) annual global air to land carbon flux. Color code for model types is as in Fig. 1.

CMIP3/C ${ }^{4}$ MIP emulation with MAGICC6 is $811-$ $1170 \mathrm{ppm}$. As discussed above, the lower range of the CMIP5 ESMs is due to one single model, MRI-ESM1, which already severely underestimates the present-day atmospheric $\mathrm{CO}_{2}$ concentration. Not including this model would mean that the lower end of the MAGICC6 range is significantly lower than the lower end of the CMIP5 ESMs.

The warming ranges simulated by the CMIP5 ESMs and by the CMIP3/C ${ }^{4} \mathrm{MIP}$ model emulations are quite similar (Figs. $2 \mathrm{~b}$ and $2 \mathrm{~d}$ ). The first set of models displays a full range of $2.5^{\circ}-5.6^{\circ} \mathrm{C}$, while the latter set has a $90 \%$ probability range of $2.9^{\circ}-5.9^{\circ} \mathrm{C}$.

\section{Twenty-first-century land and ocean carbon cycle}

To further understand the difference in simulated atmospheric $\mathrm{CO}_{2}$ over the twenty-first century, we analyzed the carbon budget simulated by the models, as already done for the historical period. In the E-driven runs, the ESMs simulate the atmospheric $\mathrm{CO}_{2}$ concentration as the residual of the prescribed anthropogenic emissions minus the sum of the land and ocean carbon uptakes-these latter two fluxes being interactively computed by the land and ocean biogeochemical components of the ESMs. Figure 4 shows the cumulative land and ocean carbon uptakes simulated by the CMIP5 ESMs. Any difference in simulated atmospheric $\mathrm{CO}_{2}$ comes from differences in the land or ocean uptakes.

The models show a large range of future carbon uptake, both for the land and for the ocean (Figs. 4a and $4 \mathrm{~b})$. However, for the ocean, 10 out of the 11 models have a cumulative oceanic uptake ranging between 412 and $649 \mathrm{PgC}$ by 2100 , the exception being INM-CM4.0 with an oceanic uptake of $861 \mathrm{PgC}$. As discussed in the historical section, the reasons for this large simulated uptake are unknown. The simulated land carbon fluxes show a much larger range, from a cumulative source of $165 \mathrm{PgC}$ to a cumulative sink of $758 \mathrm{PgC}$. Eight models simulate that the land acts as a carbon sink over the full period. Land is simulated to be a carbon source by two models, CESM1-BGC and NorESM1-ME, both sharing the same land carbon cycle model, and by MIROC-ESM. 
The large uncertainty in the atmosphere-land $\mathrm{CO}_{2}$ fluxes is partly due to not all models including land use changes in their calculations of their net landatmosphere carbon flux. Indeed, MRI-ESM1 and to a lesser extent BCC-CSM1 do not include land use change. Hence, these models only simulate $F_{\mathrm{Ln}}$-that is, the residual land sink term-and not surprisingly they simulate a larger-than-average land carbon sink. Nevertheless, even excluding the models that do not simulate $F_{L}$, but only $F_{\mathrm{Ln}}$, and keeping the remaining eight models that do account for land use change (and hence, should simulate comparable net flux) only reduces the range to -173 to $352 \mathrm{PgC}$ - that is, a $500-\mathrm{PgC}$ range, about twice as large as the range in ocean carbon uptake from these eight models (Table 3 ). This was also found in an analysis of the carbon cycle feedbacks in the prescribed $1 \% \mathrm{yr}^{-1} \mathrm{CO}_{2}$ increase in CMIP5 simulations (Arora et al. 2013), where the simulated range in the response of the land carbon cycle components was found to be about 4 times larger than that for the ocean carbon cycle. As the E-driven simulations are fully coupled, it is not possible to separately estimate the uncertainty arising from the carbon-concentration feedback (carbon cycle response to $\mathrm{CO}_{2}$ ) and the uncertainty arising from the carbon-climate feedback (carbon cycle response to climate). However, such separation is done for the CMIP5 $1 \% \mathrm{yr}^{-1}$ simulations in Arora et al. (2013), who found that both feedbacks contribute significantly to the overall land carbon uptake uncertainty. Jones et al. (2013) analyzed the concentration-driven CMIP5 models and found very similar results; that is, the land carbon sinks are very uncertain in the CMIP5 models across all four RCP scenarios, with the intermodel spread being much larger than the interscenario spread for land carbon uptake.

The MAGICC6 emulations of the wide range of CMIP3 and $\mathrm{C}^{4}$ MIP model simulations show a similar response, with a much larger spread for the land carbon fluxes than for the ocean carbon fluxes, with a $90 \%$ probability range of $446-897 \mathrm{PgC}$ for the ocean carbon sink and -373 to 657 for the land carbon sink. In the MAGICC6 simulations, land use change fluxes are always accounted for, in a consistent manner across all models, further indicating that the large spread of the land carbon cycle is due to the representation of the natural biogeochemical cycle, not the implementation of the land use perturbation.

Annual fluxes obviously show a similar behavior (Figs. $4 \mathrm{c}$ and $4 \mathrm{~d}$ ), with CMIP5 ESMs simulating the land being by the end of the twenty-first century either a net sink of up to $4 \mathrm{PgC} \mathrm{yr}^{-1}$ (although of decreasing amplitude for all models) or a net source of $6 \mathrm{PgC} \mathrm{yr}^{-1}$ for the MIROC-ESM model. On the ocean side, all models simulate a continuous sink across the twenty-first century, reaching $4.5-6 \mathrm{PgC} \mathrm{yr}^{-1}$ by the end of the century.

\section{Discussion}

CMIP5 earth system models still simulate a large uncertainty in $\mathrm{CO}_{2}$ projection, with more than 350-ppm uncertainty of projected $\mathrm{CO}_{2}$ concentrations by 2100 for the RCP 8.5 scenario. This large range is mainly due to the uncertainty in the land carbon cycle projections, where models do not even agree on the sign of the atmosphere-land $\mathrm{CO}_{2}$ flux by the end of the century. Whether the land would be a source or a sink of carbon by 2100 under the RCP 8.5 is unclear. A similar conclusion was reached in the $C^{4} \mathrm{MIP}$ analysis at the time of the IPCC AR4, with different models and a different emissions scenario (Friedlingstein et al. 2006).

However, here we are able to attribute some of the large spread to differences in model setup and their complexity. First, we show that out of the 11 models considered, 8 include the impact of land cover changes on simulated atmosphere-land $\mathrm{CO}_{2}$ fluxes, while the remaining 3 use prescribed LUC emissions as an external forcing. This artificially creates a large spread in the simulated atmosphere-land $\mathrm{CO}_{2}$ flux. Leaving out the models that prescribe LUC emissions externally, such that the effect of land use changes is neglected in their modeled atmosphere-land $\mathrm{CO}_{2}$ flux, the range is reduced from [ -173 to 758$]$ to [ -173 to 352$]$. Further, two of the three models that simulate a land sourceCESM1-BGC and NorESM1-ME—-share the same land surface scheme (CLM). As mentioned before, CLM has a very weak land response to $\mathrm{CO}_{2}$, because of a too-fast litter and soil carbon turnover time, combined with a nitrogen cycle that dampens the response to $\mathrm{CO}_{2}$ (Thornton et al. 2009; Zaehle et al. 2010). Hence, carbon loss from LUC and warming are expected to be larger than carbon gains because of $\mathrm{CO}_{2}$ fertilization for CESM1-BGC and NorESM1-ME. MIROC-ESM, the third model that simulates a land source by 2100 , has a relatively weak land carbon cycle response to $\mathrm{CO}_{2}$, but a very large land carbon cycle response to climate as reported before (Hajima et al. 2012; Arora et al. 2013). Arora et al. (2013) found that in the $1 \% \mathrm{yr}^{-1}$ increasing $\mathrm{CO}_{2}$ simulations, MIROC-ESM has the strongest land carbon-climate feedback among the nine ESMs compared in that study.

It is worth noting that as every ESM simulates its own climate, the model spread in land carbon response to climate is also partly due to the model-specific spatial patterns of changes in key climate drivers such as temperature and precipitation (Knutti and Sedláček 2012). 
We analyzed the performance of the CMIP5 ESMs over the historical period in terms of simulated atmospheric $\mathrm{CO}_{2}$, land, and carbon uptakes (Table 2). Although this cannot directly be used as a constraint, there is a clear correlation between $\mathrm{CO}_{2}$ simulated by 2005 and by 2100 . The models with a lower-thanobserved present-day $\mathrm{CO}_{2}$ have a lower-than-average $\mathrm{CO}_{2}$ by 2100 , and likewise, the models with higher-thanobserved $\mathrm{CO}_{2}$ by 2005 have high $\mathrm{CO}_{2}$ by 2100 , indicating that present-day observations are key constraints for the carbon cycle of ESMs. However, the models' order within these two groups is not conserved across time. Furthermore, when looking at the present-day carbon budget as simulated by the ESMs (Table 2), there is no clear relationship between the realism of the present-day land or ocean global uptake and the twenty-first-century projections, meaning that the correlation observed for $\mathrm{CO}_{2}$ might be accidental (e.g., compensation of errors between land and ocean sinks). Several model evaluation activities have been initiated over the last couple of years (e.g., Randerson et al. 2009; Cadule et al. 2010; Blyth et al. 2011; Anav et al. 2013; Cox et al. 2013), helping to gain confidence in some aspects of the simulated carbon cycle, but not yet leading to a significant reduction in uncertainty for the CMIP5 exercise. From the analysis here, it seems clear that most of the ESMs were not fully evaluated in terms of their carbon cycle response before performing and submitting the CMIP5 simulations. This might also be a side effect of the CMIP5 protocol (Taylor et al. 2012), where the core of the simulations was with prescribed $\mathrm{CO}_{2}$ concentration, leaving the carbon cycle as a nonessential element for climate simulations.

Our analyses suggest that, for the RCP8.5 scenario, the CMIP5 ESMs produce, on average, a slightly higher $\mathrm{CO}_{2}$ concentration compared to the default RCP8.5 $\mathrm{CO}_{2}$ concentrations and hence a slightly larger warming. This is similar to the outcome of the CMIP3 exercise where the Bern- $\mathrm{CC} \mathrm{CO}_{2}$ concentrations were chosen as a default for most CMIP3 models in the concentrationdriven runs, but the $\mathrm{C}^{4} \mathrm{MIP}$ intercomparison suggested that this choice was producing slightly below-average $\mathrm{CO}_{2}$ concentrations. This is somewhat replicated this time for CMIP5, given that the carbon cycle of MAGICC6 was calibrated to BERN-CC in order to produce the GHG concentrations of the RCPs (Meinshausen et al. 2011c). In other words, the default dataset implied again slightly lower $\mathrm{CO}_{2}$ concentrations for the concentration-driven runs than what CMIP5 ESMs suggest for emission-driven runs.

However, we also find that most of the models that simulate high-end $\mathrm{CO}_{2}$ in 2100 overestimate the presentday $\mathrm{CO}_{2}$ concentration, suggesting that either these models

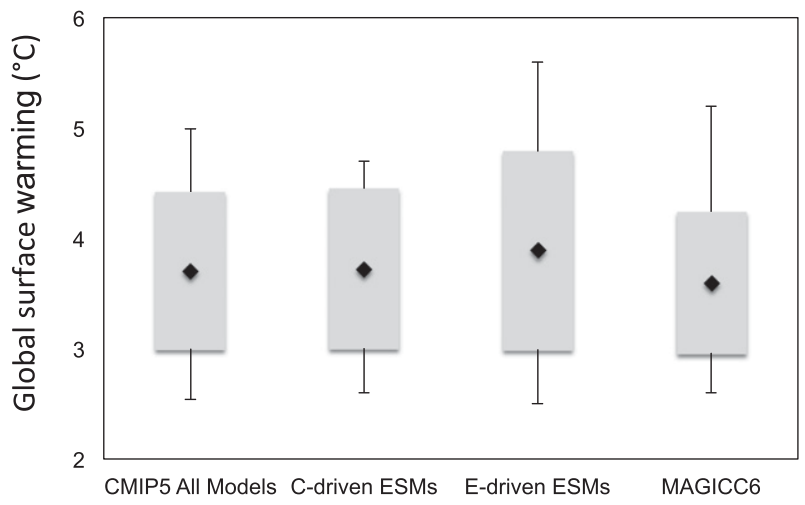

FIG. 5. Model estimate of 2100 warming relative to present day (average, standard deviation, and full range) for the C-driven runs from the CMIP5 models (full database available), for the 11 CMIP5 ESMs in C-driven-run mode, for the same 11 models, but in E-driven-run model, and from the CMIP3/ $\mathrm{C}^{4} \mathrm{MIP}$ emulation using MAGICC6.

underestimate the land and/or ocean carbon sinks or that the emissions used to drive the ESMs are slightly overestimated, casting some doubts on the added realism of emission-driven simulations when compared to concentration-driven simulations.

Temperature projected by the $11 \mathrm{ESMs}$ driven by $\mathrm{CO}_{2}$ emissions is on the average higher than when driven by $\mathrm{CO}_{2}$ concentration (Fig. 5). When compared to the temperature change simulated by all RCP8.5 C-driven simulations available (not just the ones from the 11 ESMs used here), we find that the C-driven runs from the ESMs analyzed here produce a very similar warming than the full CMIP5 database (Knutti and Sedláček 2012). When attempting to estimate the projected warming and uncertainty, from a given emission pathway, our study suggests that, for the RCP8.5 emission scenario, the best estimates of warming could be about $0.2^{\circ} \mathrm{C}$ higher than the estimate based solely on CMIP5 concentration-driven simulations. Whether this would also apply to the other RCP scenarios is unclear. Jones et al. (2013) found that, for both the RCP6.0 and RCP8.5, the ESMs derived compatible emissions were, on the average, lower than the one estimated by the integrated assessment models, consistent with our estimate that the ESMs simulate larger $\mathrm{CO}_{2}$ when using these prescribed emissions. However, this was not the case for the RCP2.6 and RCP4.5, where Jones et al. (2013) found no significant difference in terms of derived emissions.

Finally, while for the SRES scenarios the concentrationdriven experimental setup was often seen as a compromise (as most models could then, as today, not be driven by $\mathrm{CO}_{2}$ emissions), the CMIP5 exercise embraced the philosophy of concentrations-driven runs more consistently, starting with representative "concentration" pathways. 
Thus, as long as the CMIP5 climate projections are clearly communicated as referring to a specific evolution of atmospheric $\mathrm{CO}_{2}$ concentrations, non- $\mathrm{CO}_{2}$ concentrations, and aerosol abundances, there is no necessity to apply any adjustments because of more developed insights in regard to concentration-carbon cycle or climate-carbon cycle feedbacks. There is, however, the new opportunity arising from these CMIP5 ESM simulations to quantify the "allowable" carbon space-that is, the cumulative emissions that are in line with one or the other concentration pathway.

Acknowledgments. We acknowledge the World Climate Research Programme's Working Group on Coupled Modelling, which is responsible for CMIP, and we thank the climate modeling groups (listed in Table 1 of this paper) for producing and making available their model output. For CMIP, the U.S. Department of Energy's Program for Climate Model Diagnosis and Intercomparison provides coordinating support and led development of software infrastructure in partnership with the Global Organization for Earth System Science Portals. PF and AA acknowledge the GREENCYCLESII, COMBINE, and EMBRACE EU/FP7 projects. CDJ and SKL were supported by the Joint DECC/Defra Met Office Hadley Centre Climate Programme (GA01101).

\section{REFERENCES}

Adachi, Y., and Coauthors, 2013: Basic performance of a new Earth System Model of the Meteorological Research Institute (MRI-ESM1). Pap. Meteor. Geophys., in press.

Anav, A., and Coauthors, 2013: Evaluating the land and ocean components of the global carbon cycle in the CMIP5 earth system models. J. Climate, 26, 6801-6843.

Andres, R. J., J. S. Gregg, L. Losey, G. Marland, and T. A. Boden, 2011: Monthly, global emissions of carbon dioxide from fossil fuel consumption. Tellus, 63B, 309-327, doi:10.1111/ j.1600-0889.2011.00530.x.

Arora, V. K., and G. J. Boer, 2010: Uncertainties in the 20th century carbon budget associated with land use change. Global Change Biol., 16, 3327-3348.

- and Coauthors, 2011: Carbon emission limits required to satisfy future representative concentration pathways of greenhouse gases. Geophys. Res. Lett., 38, L05805, doi:10.1029/ 2010GL046270.

— , and Coauthors, 2013: Carbon-concentration and carbonclimate feedbacks in CMIP5 earth system models. J. Climate, 26, 5289-5314.

Blyth, E., D. B. Clark, R. Ellis, C. Huntingford, S. Los, M. Pryor, M. Best, and S. Sitch, 2011: A comprehensive set of benchmark tests for a land surface model of simultaneous fluxes of water and carbon at both the global and seasonal scale. Geosci. Model Dev., 4, 255-269.

Bonan, G. B., M. D. Hartman, W. J. Parton, and W. R. Wieder, 2013: Evaluating litter decomposition in earth system models with long-term litterbag experiments: An example using the
Community Land Model version 4 (CLM4). Global Change Biol., 19, 957-974, doi:10.1111/gcb.12031.

Bony, S., and Coauthors, 2006: How well do we understand and evaluate climate change feedback processes? J. Climate, 19, 3445-3482.

Cadule, P., P. Friedlingstein, L. Bopp, S. Sitch, C. D. Jones, P. Ciais, S. L. Piao, and P. Peylin, 2010: Benchmarking coupled climatecarbon models against long-term atmospheric $\mathrm{CO}_{2}$ measurements. Global Biogeochem. Cycles, 24, GB2016, doi:10.1029/ 2009GB003556.

Collins, W. J., and Coauthors, 2011: Development and evaluation of an earth-system model-HadGEM2. Geosci. Model Dev., 4, 1051-1075.

Cox, P. M., D. Pearson, B. B. Booth, P. Friedlingstein, C. Huntingford, C. D. Jones, and C. M. Luke, 2013: Sensitivity of tropical carbon to climate change constrained by carbon dioxide variability. Nature, 494, 341-344, doi:10.1038/nature11882.

Cramer, W., and Coauthors, 2001: Global response of terrestrial ecosystem structure and function to $\mathrm{CO}_{2}$ and climate change: Results from six dynamic global vegetation models. Global Change Biol., 7, 357-373.

Denman, K. L., and Coauthors, 2007: Coupling between changes in the climate system and biogeochemistry. Climate Change 2007: The Physical Science Basis, S. Solomon et al., Eds., Cambridge University Press, 499-587.

Dufresne, J.-L., and Coauthors, 2013: Climate change projections using the IPSL-CM5 earth system model: From CMIP3 to CMIP5. Climate Dyn., 40, 2123-2165.

Dunne, J., and Coauthors, 2013: GFDL's ESM2 global coupled climate-carbon earth system models. Part II: Carbon system formulation and baseline simulation characteristics. J. Climate, 26, 2247-2267.

Forster, P. M. D., and K. E. Taylor, 2006: Climate forcings and climate sensitivities diagnosed from coupled climate model integrations. J. Climate, 19, 6181-6194.

Friedlingstein, P., I. Y. Fung, E. A. Holland, J. G. John, G. P. Brasseur, D. J. Erickson, and D. S. Schimel, 1995: On the contribution of $\mathrm{CO}_{2}$ fertilization to the missing biospheric sink. Global Biogeochem. Cycles, 9, 541-556.

— , and Coauthors, 2006: Climate-carbon cycle feedback analysis: Results from the $\mathrm{C}^{4} \mathrm{MIP}$ model intercomparison. J. Climate, 19, 3337-3353.

- and Coauthors, 2010: Update on $\mathrm{CO}_{2}$ emissions. Nat. Geosci., 3, 811-812.

Gillet, N. P., V. K. Arora, D. Matthews, and M. R. Allen, 2013: Constraining the ratio of global warming to cumulative $\mathrm{CO}_{2}$ emissions using CMIP5 simulations. J. Climate, 26, 6844-6858.

Gregory, J. M., C. D. Jones, P. Cadule, and P. Friedlingstein, 2009: Quantifying carbon cycle feedbacks. J. Climate, 22, 52325250.

Hajima, T., T. Ise, K. Tachiiri, E. Kato, S. Watanabe, and M. Kawamiya, 2012: Climate change, allowable emission, and earth system response to representative concentration pathway scenarios. J. Meteor. Soc. Japan, 90, 417-433.

Hawkins, E., and R. Sutton, 2009: The potential to narrow uncertainty in regional climate predictions. Bull. Amer. Meteor. Soc., 90, 1095-1107.

Hibbard, K. A., G. A. Meehl, P. Cox, and P. Friedlingstein, 2007: A strategy for climate change stabilization experiments. Eos, Trans. Amer. Geophys. Union, 88, 217-221, doi:10.1029/ 2007EO200002.

Houghton, J. T., Y. Ding, D. J. Griggs, M. Noguer, P. J. van der Linden, X. Dai, K. Maskell, and C. A. Johnson, Eds., 2001: 
Climate Change 2001: The Scientific Basis. Cambridge University Press, $881 \mathrm{pp}$.

Houghton, R. A., 2010: How well do we know the flux of $\mathrm{CO}_{2}$ from land-use change? Tellus, 62B, 337-351, doi:10.1111/ j.1600-0889.2010.00473.x.

Hurtt, G. C., S. Frolking, M. G. Fearon, B. Moore, E. Shevliakova, S. Malyshev, S. W. Pacala, and R. A. Houghton, 2006: The underpinnings of land-use history: Three centuries of global gridded land-use transitions, wood-harvest activity, and resulting secondary lands. Global Change Biol., 12, 1208-1229, doi:10.1111/j.1365-2486.2006.01150.x.

Ilyina, T., K. D. Six, J. Segschneider, E. Maier-Reimer, H. Li, and I. Núñez-Riboni, 2013: Global ocean biogeochemistry model HAMOCC: Model architecture and performance as component of the MPI-Earth System Model in different CMIP5 experimental realizations. J. Adv. Model. Earth Syst., 5, 287-315, doi:10.1029/2012MS000178.

Jones, C. D., P. M. Cox, and C. Huntingford, 2006: Climate-carbon cycle feedbacks under stabilization: Uncertainty and observational constraints. Tellus, 58B, 603-613.

Jones, C. J., and Coauthors, 2013: Twenty-first-century compatible $\mathrm{CO}_{2}$ emissions and airborne fraction simulated by CMIP5 earth system models under four representative concentration pathways. J. Climate, 26, 4398-4413.

Joos, F., I. C. Prentice, S. Sitch, R. Meyer, G. Hooss, G.-K. Plattner, S. Gerber, and K. Hasselmann, 2001: Global warming feedbacks on terrestrial carbon uptake under the Intergovernmental Panel on Climate Change (IPCC) emission scenarios. Global Biogeochem. Cycles, 15, 891-907.

Keppel-Aleks, G., and Coauthors, 2013: Atmospheric carbon dioxide variability in the Community Earth System Model: Evaluation and transient dynamics during the twentieth and twenty-first centuries. J. Climate, 26, 4447-4475.

Knutti, R., and J. Sedláček, 2012: Robustness and uncertainties in the new CMIP5 climate model projections. Nat. Climate Change, 3, 369-373, doi:10.1038/nclimate1716.

— , and Coauthors, 2008: A review of uncertainties in global temperature projections over the twenty-first century. J. Climate, 21, 2651-2663.

Le Quéré, C., and Coauthors, 2009: Trends in the sources and sinks of carbon dioxide. Nat. Geosci., 2, 831-836, doi:10.1038/ ngeo689.

_ - and Coauthors, 2012: The global carbon budget 1959-2011. Earth Syst. Sci. Data Discuss., 5, 1107-1157.

Long, M. C., K. Lindsay, S. Peacock, J. K. Moore, and S. C. Doney, 2013: Twentieth-century oceanic carbon uptake and storage in CESM1(BGC). J. Climate, 26, 6775-6800.

Matthews, H. D., 2005: Decrease of emissions required to stabilize atmospheric $\mathrm{CO}_{2}$ due to positive carbon cycle-climate feedbacks. Geophys. Res. Lett., 32, L21707, doi:10.1029/ 2005GL023435.

_ 2006: Emissions targets for $\mathrm{CO}_{2}$ stabilization as modified by carbon cycle feedbacks. Tellus, 58B, 591-602.

McGuire, A. D., and Coauthors, 2001: Carbon balance of the terrestrial biosphere in the twentieth century: Analyses of $\mathrm{CO}_{2}$, climate and land use effects with four process-based ecosystem models. Global Biogeochem. Cycles, 15, 183206.

Meehl, G. A., and Coauthors, 2007: Global climate projections. Climate Change 2007: The Physical Science Basis, S. Solomon et al., Eds., Cambridge University Press, 747-845.

Meinshausen, M., S. C. B. Raper, and T. M. L. Wigley, 2011a: Emulating coupled atmosphere-ocean and carbon cycle models with a simpler model, MAGICC6-Part 1: Model description and calibration. Atmos. Chem. Phys., 11, 1417-1456.

T. M. L. Wigley, and S. C. B. Raper, 2011b: Emulating atmosphere-ocean and carbon cycle models with a simpler model, MAGICC6-Part 2: Applications. Atmos. Chem. Phys., 11, 1457-1471.

- and Coauthors, 2011c: The RCP greenhouse gas concentrations and their extension from 1765 to 2300 . Climatic Change, 109, 213-241, doi:10.1007/s10584-011-0156-z.

Moss, R. H., and Coauthors, 2010: The next generation of scenarios for climate change research and assessment. Nature, 463, 747756.

Nakicenovic, N., and R. Swart, Eds., 2000: Special Report on Emissions Scenarios. Cambridge University Press, 599 pp.

Orr, J. C., and Coauthors, 2001: Estimates of anthropogenic carbon uptake from four three-dimensional global ocean models. Global Biogeochem. Cycles, 15, 43-60.

Peters, G. P., G. Marland, C. Le Quéré, T. Boden, J. G. Canadell, and M. R. Raupach, 2012: Rapid growth in $\mathrm{CO}_{2}$ emissions after the 2008-2009 global financial crisis. Nat. Climate Change, 2, 2-4, doi:10.1038/nclimate1332.

Prentice, I. C., and Coauthors, 2001: The carbon cycle and atmospheric carbon dioxide. Climate Change 2001: The Scientific Basis, J. T. Houghton et al., Eds., Cambridge University Press, 183-238.

Randerson, J. T., and Coauthors, 2009: Systematic assessment of terrestrial biogeochemistry in coupled climate-carbon models. Global Change Biol., 15, 2462-2484, doi:10.1111/ j.1365-2486.2009.01912.x.

Sabine, C. L., and Coauthors, 2004: The oceanic sink for anthropogenic $\mathrm{CO}_{2}$. Science, 305, 367-371.

Shevliakova, E., and Coauthors, 2009: Carbon cycling under 300 years of land use change: Importance of the secondary vegetation sink. Global Biogeochem. Cycles, 23, GB2022, doi:10.1029/ $2007 \mathrm{~GB} 003176$.

Sitch, S., and Coauthors, 2008: Evaluation of the terrestrial carbon cycle, future plant geography, and climate-carbon cycle feedbacks using five dynamic global vegetation models (DGVMs). Global Change Biol., 14, 2015-2039, doi:10.1111/ j.1365-2486.2008.01626.x.

Solomon, S., D. Qin, M. Manning, Z. Chen, M. Marquis, K. Averyt, M. Tignor, and H. L. Miller Jr., Eds., 2007: Climate Change 2007: The Physical Science Basis. Cambridge University Press, 996 pp.

Taylor J. A., and J. Lloyd, 1992: Sources and sinks of atmospheric $\mathrm{CO}_{2}$. Aust. J. Bot., 40, 407-418.

Taylor, K. E., R. J. Stouffer, and G. A. Meehl, 2012: An overview of CMIP5 and the experiment design. Bull. Amer. Meteor. Soc., 93, 485-498.

Tebaldi, C., and R. Knutti, 2007: The use of the multi-model ensemble in probabilistic climate projections. Philos. Trans. Roy. Soc. London, A365, 2053-2075, doi:10.1098/rsta.2007.2076.

Thompson, M. V., J. T. Randerson, C. M. Malmström, and C. B. Field, 1996: Change in net primary production and heterotrophic respiration: How much is necessary to sustain the terrestrial carbon sink? Global Biogeochem. Cycles, 10, 711-726.

Thornton, P., and Coauthors, 2009: Carbon-nitrogen interactions regulate climate-carbon cycle feedbacks: Results from an atmosphere-ocean general circulation model. Biogeosciences, $\mathbf{6}$, 2099-2120, doi:10.5194/bg-6-2099-2009.

Tjiputra, J. F., C. Roelandt, M. Bentsen, D. M. Lawrence, T. Lorentzen, J. Schwinger, Ø. Seland, and C. Heinze, 2012: Evaluation of the carbon cycle components in the Norwegian 
Earth System Model (NorESM). Geosci. Model Dev. Discuss., 5, 3035-3087.

Todd-Brown, K. E. O., J. T. Randerson, W. M. Post, F. M. Hoffman, C. Tarnocai, E. A. G. Schuur, and S. D. Allison, 2013: Causes of variation in soil carbon predictions from CMIP5 earth system models and comparison with observations. Biogeosciences, 10, 1717-1736, doi:10.5194/bg-10-1717-2013.

van Vuuren, D. P., and Coauthors, 2011: The representative concentration pathways: An overview. Climatic Change, 109, 531, doi:10.1007/s10584-011-0148-z.

VEMAP members, 1995: Vegetation/Ecosystem Modeling and Analysis Project: Comparing biogeography and biogeochemistry models in a continental-scale study of terrestrial ecosystem responses to climate change and $\mathrm{CO}_{2}$ doubling. Global Biogeochem. Cycles, 9, 407-437.

Volodin, E. M., N. A. Dianskii, and A. V. Gusev, 2010: Simulating present-day climate with the INMCM4.0 coupled model of the atmospheric and oceanic general circulations. Izv. Atmos. Oceanic Phys., 46, 414-431.
Watanabe, S., and Coauthors, 2011: MIROC-ESM 2010: Model description and basic results of CMIP5-20c3m experiments. Geosci. Model Dev., 4, 845-872.

Wu, T., and Coauthors, 2010: The Beijing Climate Center atmospheric general circulation model: Description and its performance for the present-day climate. Climate Dyn., 34, 123-147, doi:10.1007/s00382-008-0487-2.

Xin, X., L. Zhang, J. Zhang, T. Wu, and Y. Fang, 2013a: Climate change projections over East Asia with BCC_CSM1.1 climate model under RCP scenarios. J. Meteor. Soc. Japan, 91, 413-429.

Xin, X.-G., T.-W. Wu, J.-L. Li, Z.-Z. Wang, W.-P. Li, and F.-H. Wu, 2013b: How well does BCC_CSM1.1 reproduce the 20th century climate change over China? Atmos. Oceanic Sci. Lett., 6, 21-26.

Zaehle, S., P. Friedlingstein, and A. D. Friend, 2010: Terrestrial nitrogen feedbacks may accelerate future climate change. Geophys. Res. Lett., 37, L01401, doi:10.1029/ 2009 GL041345. 